\title{
De novo oviduct transcriptome of the moor frog Rana arvalis: a quest for maternal effect candidate genes
}

\author{
Longfei Shu ${ }^{\text {Corresp., }}{ }^{1,2}$, Jie Qiu ${ }^{3}$, Katja Räsänen ${ }^{1,2}$ \\ ${ }^{1}$ Institute of integrative Biology, Swiss Federal Institute of Technology, Zurich, Zurich, Switzerland \\ 2 Department of Aquatic Ecology, Eawag, Dübendorf, Switzerland \\ 3 Institutue of Crop Science \& Institute of Bioinformatics, College of Agriculture and Biotechnology, Zhejiang University, Hangzhou, China \\ Corresponding Author: Longfei Shu \\ Email address: LONGFEI.SHU@WUSTL.EDU
}

Maternal effects can substantially affect ecological and evolutionary processes in natural populations. However, as they often are environmentally induced, establishing their genetic basis is challenging. One important, but largely neglected, source of maternal effects are egg coats (i.e. the maternally derived extracellular matrix that surrounds the embryo). In Rana arvalis, the gelatinous egg coats (i.e. egg jelly) are produced in the mother's oviduct and consist primarily of highly glycosylated mucin type O-glycans. These O-glycans affect jelly water balance and, subsequently, strongly contribute to adaptive divergence in embryonic acid tolerance. To identify candidate genes for maternal effects, we conducted RNAseq transcriptomics on oviduct samples from seven $R$. arvalis females, representing the full range of within and among population variation in embryonic acid stress tolerance across our study populations. De novo sequencing of these oviduct transcriptomes detected 124071 unigenes and functional annotation analyses identified a total of 57839 unigenes, of which several identified genes likely code for variation in egg jelly coats. These belonged to two main groups: mucin type core protein genes and five different types of glycosylation genes. We further predict 26711 gene-linked microsatellite (SSRs) and 231274 single nucleotide (SNPs) polymorphisms. Our study provides the first set of genomic resources for $R$. arvalis, an emerging model system for the study of ecology and evolution in natural populations, and gives insight into the genetic architecture of egg coat mediated maternal effects. 


\section{Affiliations:}

$5 \quad$ 'Eawag, Department of Aquatic Ecology, Dübendorf, Switzerland

$6 \quad{ }^{2}$ ETH Zürich, Institute of Integrative Biology, Zürich, Switzerland

$7 \quad{ }^{3}$ Institutue of Crop Science \& Institute of Bioinformatics, College of Agriculture and

8 Biotechnology, Zhejiang University, Hangzhou, China maternal effect candidate genes

Longfei Shu*1,2, Jie Qiu ${ }^{3}$ and Katja Räsänen ${ }^{1,2}$
9

10

\section{Corresponding author:}

Dr. Longfei Shu

Eawag, Department of Aquatic Ecology, Switzerland and ETH Zürich, Institute of Integrative Biology, CH-8600 Dübendorf, Switzerland;

Email: longfei.shu@wustl.edu; Phone: +1-314-445-8037.

*Current address: Department of Biology, Washington University in St. Louis, St. Louis, MO 63130, USA 


\section{Abstract}

Maternal effects can substantially affect ecological and evolutionary processes in natural populations. However, as they often are environmentally induced, establishing their genetic basis is challenging. One important, but largely neglected, source of maternal effects are egg coats (i.e. the maternally derived extracellular matrix that surrounds the embryo). In Rana arvalis, the gelatinous egg coats (i.e. egg jelly) are produced in the mother's oviduct and consist primarily of highly glycosylated mucin type O-glycans. These O-glycans affect jelly water balance and, subsequently, strongly contribute to adaptive divergence in embryonic acid tolerance.

To identify candidate genes for maternal effects, we conducted RNAseq transcriptomics on oviduct samples from seven $R$. arvalis females, representing the full range of within and among population variation in embryonic acid stress tolerance across our study populations. De novo sequencing of these oviduct transcriptomes detected 124071 unigenes and functional annotation analyses identified a total of 57839 unigenes, of which several identified genes likely code for variation in egg jelly coats. These belonged to two main groups: mucin type core protein genes and five different types of glycosylation genes. We further predict 26711 gene-linked microsatellite (SSRs) and 231274 single nucleotide (SNPs) polymorphisms.

Our study provides the first set of genomic resources for $R$. arvalis, an emerging model system for the study of ecology and evolution in natural populations, and gives insight into the genetic architecture of egg coat mediated maternal effects.

\section{Background}

Understanding evolutionary processes of natural populations necessitates a good understanding of the genetic architecture of trait variation in an ecologically relevant context (e.g. (Houle et al. 2010; Mitchell-Olds et al. 2007; Nadeau \& Jiggins 2010)). Maternal effects (the effects of a mother's environment and phenotype on offspring performance) are an important source of phenotypic variation and often under strong natural selection (reviewed in (Mousseau \& Fox 
52 1998; Räsänen \& Kruuk 2007)). Maternal effects can influence speed and direction of evolution 53 as well as facilitate local adaptation (Hangartner et al. 2012; Räsänen \& Kruuk 2007; Shu et al.

54

55

56

57

58

59

60

61

62

63

64

2016; Wolf et al. 1998). However, as maternal effects are typically at least partially environmentally induced, their genetic architecture is poorly understood.

Maternal effects can arise through various mechanisms, most commonly acknowledged through variation in egg size and content (reviewed in (Bernardo 1996; Mousseau \& Fox 1998). A much less well acknowledged but important source of maternal effects are so called egg coats (Shu et al. 2015b). Egg coats (present in all sexually reproducing animals, as well as many asexual metazoans) are maternally derived, extracellular structures that consist of multiple functionally and structurally different layers (reviewed in (Menkhorst \& Selwood 2008; Shu et al. 2015b; Wong \& Wessel 2006)). These structures have many key functions, ranging from fertilization to embryonic protection (Shu et al. 2015b). The genetic basis of the innermost, so called oocyte coats, has been studied in several model systems, such as sea urchins and the abalone (Claw \& Swanson 2012; Palumbi 2009), the moth Bombyx mori (Papantonis et al. 2015) and the frog Xenopus laevis (Hedrick 2008; Shu et al. 2015b). However, the genetic basis of outermost gelatinous egg coats, often found in taxa where embryos develop externally in the surrounding environment (e.g. various invertebrates, fish, and amphibians), is to date effectively unstudied (reviewed in (Shu et al. 2015b)).

In the moor frog Rana arvalis, jelly coat mediated maternal effects have driven adaptive divergence in embryonic acid stress tolerance (Hangartner et al. 2011; Persson et al. 2007; Räsänen et al. 2003b; Shu et al. 2015a; Shu et al. 2016; Shu et al. 2015c). This divergence is primarily due to glycoproteins of the jelly coats, which influence water balance and, subsequently, embryonic survival in acidic conditions (Shu et al. 2015a). Egg jelly glycoproteins are complex glycan structures attached to a protein backbone (Hedrick \& Nishihara 1991) and are highly species specific (Coppin et al. 1999; Delplace et al. 2002; Strecker et al. 2003). Given this complexity, the jelly coats can be coded by multiple genes that regulate - for instance - the protein backbone and the activities of enzymes that impact how different branches are attached (Shu et al. 2015b). This makes identifying the genetic basis of jelly coat variability highly challenging - particularly so in natural populations not amenable to experimental crossgenerational rearing or genetic manipulations. Here next generation sequencing tools, in particular RNA-seq, can be helpful (Todd et al. 2016; Wang et al. 2009). Here we applied de 
83 novo transcriptomics to get first insight to jelly coat genes in $R$. arvalis. We conducted tissue 84 specific RNA-seq of $R$. arvalis oviducts, where jelly coat biosynthesis takes place (Hedrick \& 85 Nishihara 1991).

86 Despite the increasing numbers of genomes being sequenced, the genomic resources for amphibians are sparse and only a handful of amphibian genomes have been sequenced so far (Elewa et al. 2017; Hammond et al. 2017; Hellsten et al. 2010; Nowoshilow et al. 2018; Sun et al. 2015). This is an important shortcoming, given that amphibians are common model systems for a range of ecotoxicological (Helbing 2012), ecological and evolutionary studies, the latter ranging from spatial patterns of phenotypic and genetic divergence (Egea-Serrano et al. 2014; Richter-Boix et al. 2011; Van Buskirk \& Arioli 2005) to developmental plasticity (GomezMestre et al. 2006) and adaptive maternal effects (Mousseau \& Fox 1998; Räsänen et al. 2003b; Shu et al. 2016; Shu et al. 2015c).

To bridge this knowledge gap - and as a first step to identify candidate genes for egg coat mediated maternal effects - we here apply tissue specific transcriptomics on $R$. arvalis oviducts. In doing so, we complement recent transcriptomics studies on other ranid species (Birol et al. 2015; Helbing 2012; Price et al. 2015; Qiao et al. 2013; Robertson \& Cornman 2014; Zhang et al. 2013) and increase availability of genomics resources for amphibians in general. As our specific interest is in identifying putative genes underlying egg jelly coat variation, we collected samples from the oviduct on seven $R$. arvalis individuals encompassing the full range of embryonic acid tolerance variation among and within our study populations (Hangartner et al. 2011; Shu et al. 2015a; Shu et al. 2015c). We focused particularly on identifying genes related to biosynthesis of mucin type O-linked glycans. In addition, this study provides the first transcriptomes for $R$. arvalis, and adds more genome wide markers in addition to existing resources (Brelsford et al. 2017).

\section{Materials and Methods}

\section{Study system}

R. arvalis is an anuran amphibian, broadly distributed across the western Palearctic (Glandt 2006). Individuals from three $R$. arvalis populations (Tottajärn, [T], Bergsjö, [B] and Stubberud, [S]) breeding in permanent ponds along an acidification gradient in southwestern Sweden were used in this study (Hangartner et al. 2011; Shu et al. 2015a; Shu et al. 2016; Shu et al. 2015b; 
113 Shu et al. 2015c). These ponds differ in $\mathrm{pH}$ due to a mix of natural acidification processes,

114 variation in bedrock buffering capacity and acid rain (Räsänen et al. 2003a; Räsänen et al.

115 2003b). These populations were chosen because, based on former common garden experiments

116 ((Hangartner et al. 2012; Shu et al. 2015c), they represent the extreme ends of adaptive

117 divergence in embryonic acid stress tolerance (i.e. [S] most acid sensitive; [B] intermediate

118 tolerance; [T] most acid tolerant). The $\mathrm{pH}$ in these ponds ranges from highly acidic ( $\mathrm{pH} 4$, site

$119[\mathrm{~T}])$ to intermediate ( $\mathrm{pH} 6$, site $[\mathrm{B}])$ to neutral ( $\mathrm{pH} 7.5$, site $[\mathrm{S}])$.

120 During the breeding season of 2012, females in breeding condition were collected and 121 transported to the laboratory at Uppsala University $\left(59^{\circ} 50^{`} \mathrm{~N}, 17^{\circ} 50^{`} \mathrm{E}\right)$. The females were

122 maintained in containers with moist Sphagnum moss (antibacterial medium) in a climate

123 chamber at $2-4^{\circ} \mathrm{C}$ until artificial crosses (see below) and RNA sampling were conducted a few

124 days later. The females used for this transcriptomics study consisted of a subset (out of 7 to 10

125 females/population) of females that were artificially crossed to establish acid tolerance of

126 embryos in a common garden laboratory experiment and to study variation in macromolecular

127 composition of egg jelly coats (for details see (Shu et al. 2016; Shu et al. 2015c)). The

128 experiments were conducted under permissions from the Västra Götaland county board

129 (collection permit: Dnr 522-6666-2011) and the Ethical committee (Dnr C65/11) for animal

130 experiments in Uppsala County.

131

132

133

134

135

136

137

138

139

140

141

142

\section{Sampling and RNA extraction}

To bracket a broad range of genetic backgrounds, a total of six females were chosen so as to represent females that produced the most acid tolerant (highest embryonic survival at acidic $\mathrm{pH}$ in a common garden experiment) and most acid sensitive (lowest embryonic survival at acidic $\mathrm{pH}$ in a common garden experiment) clutches both among and within each of the three populations (Shu et al. 2016). In addition, we included a sample from one female that had not yet fully ovulated, hence providing a reference for gene expression at an earlier stage of egg coat production (Supplementary material). For each female, RNA of the whole oviduct (i.e. specific tissue where egg jelly is produced (Hedrick \& Nishihara 1991)) was collected and stored in RNA later at $-20^{\circ} \mathrm{C}$ until extraction. RNA extraction was conducted using TRIzol (Life Technologies) according to the manufacturer's protocol, followed by DNase (Qiagen) treatment to eliminate potential genomic DNA contamination. Both the concentration and integrity of the RNA samples 
143 for transcriptomic analyses were evaluated with the Agilent 2100 Bioanalyzer. All samples had

144 an RNA integrity value (RIN) $>8$ and were, hence, used to construct the cDNA libraries

145 (Schroeder et al. 2006).

\section{6 cDNA library construction and sequencing}

147 cDNA libraries were generated using the TruSeq RNA-Seq Sample Prep kit according to the 148 manufacturer's protocol (Illumina Inc., San Diego, CA, USA). Briefly, magnetic beads with 149 Oligo (dT) were used to isolate the poly $(\mathrm{A})+\mathrm{mRNA}$. Fragmentation buffer was added in the 150 presence of divalent cations to break the mRNA into short fragments of approximately $200 \mathrm{bp}$.

151 Short fragments were purified with QiaQuick PCR extraction kit, followed by end reparation, 152 adding poly(A) and sequencing adapters. The suitable fragments were selected for the PCR 153 amplification as templates. In total, seven cDNA libraries were constructed and sequenced using 154 the Illumina HiSeq ${ }^{\mathrm{TM}} 2000$ (90 bp paired-end reads). The sequencing reactions were conducted 155 at the Beijing Genomics Institute (BGI), Shenzhen.

Assembly and annotation

157 Raw reads were filtered to remove reads containing adaptors, reads with unknown nucleotides greater than $5 \%$, and low-quality reads with more than $20 \%$ bases of quality value $\leq 10$ (filter_fq, BGI). Only clean reads were used in the following analyses. Transcriptome de novo assembly was carried out using the assembly program Trinity (Grabherr et al. 2011). Briefly, the software first combined reads of certain lengths of overlap to form contigs. Subsequently, the reads were mapped back to the contigs, which were connected until extension proceeded on neither end (Grabherr et al. 2011). After removing any redundancy, the resulting sequences were defined as unigenes. Software and their parameters were: Trinity (--seqType fq --min_contig_length 100; -min_glue 4 --group_pairs_distance 250; --path_reinforcement_distance 85 --min_kmer_cov 4); TGICL (-1 40 -c 10 -v 20); Phrap (-repeat_stringency 0.95 -minmatch 35 -minscore 35).

Unigene annotation provides information of expression and functional annotation of Unigene sequences. Unigene sequences were first annotated using blastx against the database $\mathrm{Nr}$ (http://www.ncbi.nlm.nih.gov/), with a cut-off E-value of 1e-5. To acquire a more comprehensive annotation, Unigene sequences were also aligned to the protein databases SwissProt, Kyoto Encyclopedia of Genes and Genomes (KEGG) and Gene Ontology (GO) (1e-5) by

172 blastx. In order to predict and classify the possible functions of the unigenes, they were 
173 additionally annotated to Cluster of Orthologous Group (COG), which classifies orthologous

174 gene products (Tatusov et al. 2003). Software and their parameters were: BLAST (-F F -e 1e-5 -

175 p blastn; -F F -e 1e-5 -p blastx); Blast2GO (Default); Path_finder (Default).

\section{Protein Coding Sequence Prediction (CDS)}

177 Unigenes were aligned by blastx $(e$ value $<0.00001)$ to protein databases in the priority order of

178 NR, Swiss-Prot, KEGG and COG. Unigenes aligned to a higher priority database were not

179 aligned to lower priority database. Proteins with the highest ranks in the blast results were used

180 to decide the coding region sequences of the Unigenes. The coding region sequences were

181 subsequently translated into amino acid sequences with the standard codon table. This produced

182 both the nucleotide sequences $\left(5^{\prime}->3^{\prime}\right)$ and amino acid sequences of the Unigene coding regions.

183 Unigenes that could not be aligned to any database were scanned by ESTScan (Iseli et al. 1999),

184 producing nucleotide sequence ( $5^{\prime}->3$ ') direction and amino acid sequence of the predicted

185 coding region.

\section{Metabolic pathway analysis}

187 To investigate the functions of the unigenes in metabolic processes, we acquired pathway 188 annotation by mapping the unigenes to GO and KEGG database (Kanehisa et al. 2008). GO 189 database is a relational database, which has three ontologies: molecular function, cellular 190 component, and biological process. KEGG is a database for understanding high-level functions 191 and utilities of the biological system. It is able to analyze gene products during metabolism and 192 cellular processes and allowed us to get pathway annotation for unigenes. We used the Blast2GO 193 program with default setting to acquire GO and KEGG annotation of Unigenes (Tarazona et al. 194 2011).

195

196 197

198

199 200

\section{Identification of candidate genes for maternal effects}

Based on prior work, jelly coats of $R$. arvalis and other amphibians (Coppin et al. 1999; Guerardel et al. 2000; Strecker et al. 2003) mostly consist of mucin type O-glycans, making genes related to mucins and to $\mathrm{O}-$ glycan biosynthesis particularly relevant as maternal effect genes. Therefore we considered as candidate genes related to $R$. arvalis egg jelly coats (Shu et al. 2015b) unigenes that i) were expressed in all individuals, ii) were mapped to the category of 
201 "extracellular matrix" in GO and KEGG annotations, and iii) were involved in the glycosylation 202 process.

203

204

205

206

207

208

209

210

211

212

213

214

215

216

217

218

219

220

221

222

223

224

225

226

227

228

229

\section{Preliminary differential expression analysis}

Unigene expression was calculated using the FPKM (Fragments Per kb per Million reads), which can eliminate the influence of different gene length and sequencing level on the calculation of gene expression (Mortazavi et al. 2008). Group comparison between populations was performed using the R Bioconductor package NOISeq, which is a data-adaptive and nonparametric method (Tarazona et al. 2011). We defined Probability $\geq 0.8$ and the absolute value of Log2Ratio $\geq 1$ as the threshold to judge the significance of gene expression difference between populations. KEGG enrichment analysis was performed with a Fisher's exact test in Blast2GO (Tarazona et al. 2011). Pathway enrichment analysis identifies significantly enriched metabolic pathways or signal transduction pathways in differentially expressed genes (DEGs). After correction for multiple testing, we chose pathways with $Q$ value $\leq 0.05$ as significantly enriched in DEGs (Gotz et al. 2008; Tarazona et al. 2011).

\section{Genetic marker resources}

To aid population genomic analyses for taxa for which no genome is available, RNA-seq data can be used to identify genomic markers, such as Simple sequence repeats (SSR) and Single nucleotide polymorphisms (SNPs), in transcribed regions (Lopez-Maestre et al. 2016). We therefore used the oviduct RNA-seq data to predict SSR and SNP markers, which allows later validation of targeted questions (Lopez-Maestre et al. 2016), such as allelic frequency variation of the candidate genes in the source populations.

SSRs were identified in the final assembly with the software MicroSAtellite (MISA, http://pgrc.ipk-gatersleben.de/misa/) using unigenes as the reference. Assembled contigs were scanned for SNPs with SNP detection software SOAPsnp (Li et al. 2008). The program can assemble consensus sequence for the genome of a newly sequenced individual based on the alignment of the raw sequencing reads on the unigenes. The program calculated the likelihood of each genotype at each site based on the alignment of short reads to a unigene, set together with the corresponding sequencing quality scores. It then infers the genotype with highest posterior probability at each site based on Bayes' theorem (the reverse probability model (Li et al. 2008)). 
230 Therefore, the intrinsic bias or errors that are common in Illumina sequencing data have been

231 taken into account and the quality values for use in inferring consensus sequence have been

232 recalibrated. Software and their parameters were: SOAPsnp (Release 1.03,

233 http://soap.genomics.org.cn/soapsnp.html, -u t -Q i -L 90).

234 Additional analyses

235 We performed post hoc analyses to address three additional questions. To test whether

236 embryonic acid tolerance is related to the transcriptional activity, we performed a correlation

237 analysis between the acid tolerance of each individual and the expression of each unigene

238 (FPKM) by PYTHON. A strict correlation threshold was applied (Pearson correlation, $|r|>0.9$

239 and $p$-value $<0.01$ ).

240 To test how much of the fluke genomes our $R$. arvalis dataset covers, we downloaded the

241 genomes of 3 fluke species (Clonorchis sinensis, Schistosoma mansoni, Schistosoma japonicum)

242 from the wormbase (https://parasite.wormbase.org/), and blasted each species (BLATP, E-value

$243<1 \mathrm{e}-7)$ against our unigenes dataset.

244 To examine whether there are any hits to the transcriptomic resources developed for the green

245 frog Rana clamitans and chorus frog Pseudacris regilla (Robertson \& Cornman 2014), we

246 downloaded their assembled transcriptomes from NCBI BioProjects (PRJNA162931 and

247 PRJNA163143), and blasted each species against our unigenes database (BLASTX, E-value < 248 1e-7).

\section{Results}

\section{Sequencing and assembly}

251 In total, 53330025420 bp bases were generated from the $R$. arvalis oviduct transcriptome.

252 Total clean reads of the seven cDNA libraries ranged from 81166804 to 87485924 (Table 1),

253 with an average GC content of 44.95\%. In the final assembly, 87401 to 112136 unigenes were

254 detected across the six cDNA libraries (Table 2). Interestingly, for the one female that had not

255 yet ovulated fewer unigenes (69 987) were detected than for the remaining females (that had

256 ovulated). When the cDNA libraries were pooled, a total of 124071 unigenes were detected, 
257 with an N50 of 1, $212 \mathrm{bp}$ and a total length of $90.3 \mathrm{Mb}$. The average length of the unigenes was

258728 bp (Fig. 1).

259

260

261

262

263

264

265

266

267

268

269

270

271

272

273

274

275

276

277

278

279

280

281

282

283

284

285

\section{Transcriptome annotation}

The E-value distributions of the unigenes showed that approximately $60 \%$ of the unigenes had very strong homogeny $(<1 \mathrm{e}-30)$ with the Nr database, while the rest ranged from 1e-5 to 1e-30 (Fig. 2A). Thirty percent of the unigene sequences had over $80 \%$ similarity with the Nr database, while the similarity of the remaining $70 \%$ of sequences ranged from $17 \%$ to $80 \%$ (Fig. $2 \mathrm{~B}$ ). The R. arvalis sequences matched best with Xenopus (Silurana) tropicalis (43.4\%), followed by Xenopus laevis (13.1 \%, Fig. 2C) and the liver fluke Clonorchis sinensis (12.1\% Fig. 2C). In addition, we found that the percentages of genes in three fluke genomes that have hits in our dataset were very high (C. sinensis: 61.4\%; Schistosoma mansoni: 72.3\%; S. japonicum: 58.0\%, respectively), indicating that we indeed sequenced parasites in the oviduct wild moor frogs.

Functional classes were successfully annotated for 13501 unigenes using COG (Fig. 3, 4). BLASTX against Swiss-Prot, KEGG, NT and GO database resulted in 37 262, 31 405, 39138 and 24452 hits, respectively (Fig. 4). Altogether, 57839 R. arvalis unigenes (46.6\% of all 124 071 unigenes) had significant matches with existing databases (Fig. 4). Among the 124071 unigenes, 48850 (39.4\%) were predicted as Protein coding sequences (CDS). Of these, 44809 unigenes were aligned using existing databases, while 4041 unigenes that could not be annotated with any database were predicted by EST Scan. The length distribution of the CDS protein sequences is available in the Supporting information.

\section{Functional pathway annotation}

A total of 24452 unigenes (42.27\% of all annotated unigenes) were successfully categorized into 60 GO functional groups (Fig. 5). These were classified to three major categories: biological processes (23), cellular components (18), and molecular functions (19) (Fig. 5). A total of 31405 unigenes (54.29\% of all annotated unigenes) were annotated in KEGG, and assigned to 259 known KEGG pathways (Table S2). The highly enriched pathways included: metabolic pathways $(3796,12.09 \%)$, purine metabolism $(1910,6.08 \%)$, regulation of actin cytoskeleton $(1202,3.83 \%)$, focal adhesion $(1161,3.7 \%)$, and calcium signaling pathway $(1159,3.69 \%)$.

\section{Candidate genes for egg jelly coat}


286 We identified two groups of candidate genes likely related to egg jelly coats: 1) core protein 287 genes (Table 3) and 2) protein glycosylation genes (Table 4). The major components of egg jelly

288

289

290

291

292

293

294

295

296

297

298

299

300

301

302

303

304

305

306

307

308

309

310

311

312

313

314

315

core protein (extracellular matrix fiber, ECM) are mucins (Hedrick 1991), of which 13 and 11 different types, respectively, were detected in our dataset (Table 3). Within the Mucin gene family, Mucin-5AC, Mucin-5B and Mucin-2 were very highly expressed (Table 3) and the most abundant transcripts of all unigenes. In addition, previous evidence suggests that the Mucin-5 gene is expressed exclusively in the $X$. tropicalis oviduct, making Mucin-5 genes likely candidates for egg jelly coat genes (Lang et al. 2016). Several other minor components were also identified (Dermatopontin, Fibulin-5 and Fibrinogen-like protein 1, Decorin, EMILIN-1, Fibrillin-1, Fibronectin, and Laminin) (Table 3).

In addition to the candidate core protein genes, five major biosynthesis pathways involved in protein glycosylation were identified based on KEGG: Mucin type O-Glycans, Other types of O-glycans, Heparan sulfate, Chondroitin sulfate, and Keratan sulfate (Table 4). Of these, Mucin type O-Glycan genes are the most likely candidates for egg jelly coat glycosylation (Coppin et al. 1999; Lang et al. 2016) (Fig. 6). Of the eight types of Mucin type O-Glycans, only genes related to cores 1, 2, 3, 4, and 6 Mucin type O-Glycan biosynthesis were detected, while cores 5, 7, and 8 were not expressed in R. arvalis (Fig. 6).

\section{Preliminary differential expression analysis}

Differentially expressed genes (i.e. DEGs) were identified by pairwise comparisons between each population pair ([S] vs [T], [S] vs [B], [T] vs [B]) of six of the females (the not ovulated female was excluded from these analyses). Overall, 4457, 4198, and 3691 differentially expressed genes were identified between [S] vs [T], [S] vs [B], and [T] vs [B], respectively (Figure S3). In general, [T] and [B] individuals had much lower gene expression levels compared to S individuals (Figure S3). For instance, 3397 and 3388 genes were down-regulated in the [T] and [B] individuals compared to the [S] individuals, while only 1060 and 810 genes were upregulated in [T] individuals compared to the $[\mathrm{S}]$ individuals (Figure S3). The smallest number of differentially expressed genes occurred between the [T] and [B] individuals, where 2256 were up-regulated and 1435 were down-regulated in [T] versus [B] individuals (Figure S3).

Enrichment of KEGG pathway in the differentially expressed unigenes was assessed using a Fisher's exact test (FDR < 0.05). The FDR analyses identified 37 and 49 significantly enriched 
316 KEGG pathways in [T] (Table S4) and [B] (Table S3) compared to [S] individuals, whereas only

317 two were identified between [T] and [B] (Table S5). Again, the suggested expression profiles of

$318[\mathrm{~T}]$ and $[\mathrm{B}]$ individuals were more divergent compared to that of $[\mathrm{S}]$ individuals, while

319 differentiation between the [T] vs.[B] was very small. The Ribosome (KO03010) and Oxidative

320 phosphorylation (KO00190) were the most enriched pathways in both [S] vs. [T] and [S] vs. [B]

321 comparisons (Table S3, S4). This indicated that [T] and [B] females had, in general, lower rates

322 of energy production as well as protein biosynthesis.

323 Because we are able to rank each individual frog's degree of acid tolerance based on our 324 previous work (Shu et al. 2016), we can test whether a frog's acid tolerance is related to the 325 transcriptional activity. The correlation analyses found 292 unigenes that were significantly

326 correlated with acid tolerance. These genes have diverse functions ranging from signaling to 327 protein biosynthesis, which could be suitable targets for future functional work (SI2). However, 328 future studies are needed to confirm their functional correlations. The information of candidate 329 genes was listed in Supplementary Information 2 (SI2).

\section{SSRs and SNPs}

331 A total of 26711 SSRs were identified across all unigenes, in which Mono-nucleotide repeats 332 (19 215), Di-nucleotide repeats (5 050), and Tri-nucleotide repeats (2 002) were the most 333 abundant SSR motif classes, and Quad-nucleotide repeat (345), Penta-nucleotide repeats (79), 334 and Hexa-nucleotide repeats (20) were detected at much lower frequencies (Fig. S1, Table S1). A total of 231274 SNPs were predicted across all unigenes. The number of SNPs in seven individual cDNA libraries ranged from 63354 to 86608 (Fig. S2). The average Ts/Tv ratio (the numbers of transitions and transversions at the SNP sites) of all SNPs was ca. 1.75.

338

339

340

341

342

343
Due to a small sample size, the SSR and SNP data were not analyzed in detail for segregation among populations. However, as a first step we compared the homologous SNPs differentiated between population [S] (most acid sensitive) and population [T] (most acid tolerant) that differ in acid tolerance. We found 420 candidate SNPs that could be suitable targets for future functional work. The results are listed in Supplementary Information 3 (SI3). 
344 Understanding the genetic architecture of maternal effects is important for our ability to

345 understand the relative contribution of genetic versus plastic effects in organismal phenotypes 346 and the eco-evolutionary processes of natural populations (Mousseau \& Fox 1998; Räsänen \&

347 Kruuk 2007). Yet given that maternal effects are typically strongly environmentally induced, and

348 that the phenotypic variance of offspring is produced in the mother but their fitness consequences 349 expressed in the offspring, establishing their genetic basis is challenging - particularly in non350 model systems. We therefore applied RNA-seq analyses as a first step towards identifying 351 candidate genes for maternal effects that are mediated through the gelatinous egg coats (i.e. egg 352 jelly) in $R$. arvalis (Shu et al. 2015b). We next provide an overview of the general genomic 353 variation revealed, followed by a discussion of putative candidate genes for maternal effects.

\section{General genomic aspects}

355 We characterized 124071 unigenes from the $R$. arvalis transcriptome, and successfully 356 annotated 57839 of them (46.6\%). It is somewhat surprising that a substantial portion of the 357 unigenes matched to a trematode parasite (Platyhelminthes) rather than any vertebrate genomes.

358 Given that the Xenopus genomes are well annotated, it is possible that we have produced two 359 transcriptomes here: $R$. arvalis and trematode parasite (an approach that was recently used to detect endoparasites (Santos et al. 2018)). Our additional analysis confirmed the presence of trematode parasites. However, we can't distinguish the exact trematode species that infected our frog. Trematode parasites are common in amphibians (Sears et al. 2012), but to our knowledge nothing is known of the oviduct parasites in $R$. arvalis.

364 The lack of amphibian genomes is mostly due to their large genome sizes (due to large proportion of repeat sequences (Sun et al. 2015)). Yet clearly more work on amphibian genomics is needed as 1) amphibians are the most ancient class of land-dwelling vertebrates and their genomic resources are essential for understanding vertebrate development and evolution; 2) the understanding of evolutionary processes of amphibian populations would greatly be facilitated by studies on the genomic architecture of trait variation, and 3) because conservation of amphibians that are under serious global decline (Hof et al. 2011; Stuart et al. 2004) could thus be facilitated (Calboli et al. 2011). The recently sequenced transcriptomes of $R$. arvalis (this study) and other Ranidae (Birol et al. 2015; Helbing 2012; Price et al. 2015; Qiao et al. 2013; Robertson \& Cornman 2014; Zhang et al. 2013) will aid in developing amphibian genomics 
374 resources. As we used only oviduct tissue, while most other studies use other tissues (e.g. liver,

375 skin), a comparison of oviduct-specific transcriptomes with transcriptomes from other tissues is 376 needed to reliably identify oviduct-specific genes or expression profiles. For instance, when

377 compared with the recently developed transcriptomic resources for the green frog Rana

378 clamitans and chorus frog Pseudacris regilla (Robertson \& Cornman 2014), the percentage of

379 genes in our dataset that have hits in their dataset are 40.61\% (20 402/50 238) and 40.62\% (19

$380583 / 48$ 213) respectively, indicating a considerable proportion of candidate oviduct-specific

381 genes. Furthermore, the large number of potentially amplifiable SSRs and SNP markers detected

382 in this study (Supporting information) represent an important resource for applications in

383 population genetics and for the detection of interesting functional genetic variants (Li et al. 2008;

384 Morin et al. 2004; Schunter et al. 2014).

385

386

387

388

389

390

391

392

393

394

395

396

397

398

399

400

401

402

403

\section{Candidate genes for maternal effects: inside the egg jelly coat}

Although there is substantial potential for a genetic basis in maternal effects (Räsänen \& Kruuk 2007), most studies aiming to identify maternal effect genes have focused on their role in early embryonic development per se (Tong et al. 2000; Wu et al. 2003). To what extent maternal effect genes contribute to adaptive divergence of local populations and response to natural selection at early life stages is therefore still largely unknown.

We identified two groups of candidate maternal effect genes based on their role in egg jelly biosynthesis: mucin core protein genes and protein glycosylation genes. The mucin genes and Olinked glycosylation genes are particularly likely candidates, given that amphibian egg jelly including that of $R$. arvalis (Coppin et al. 1999a) - mostly consists of mucin type O-linked glycoproteins (Coppin et al. 1999; Guerardel et al. 2000; Strecker et al. 2003). Evidence for high mucin gene expression in the oviduct has been found previously in Rana chensinensis (Zhang et al. 2013) and $X$. tropicalis (Lang et al. 2016). Whereas Mucin 2 is expressed in various tissues, Mucin 5AC was reported to be exclusively expressed in the oviduct of $X$. tropicalis. Although Mucins, particularly Mucin 5, are likely candidates for the core protein in jelly coats, the role of different genes contributing to the glycosylation of the jelly coat proteins are much more difficult to infer. For instance, the egg jelly coat of $R$. arvalis consists of at least 19 different glycan building blocks (Coppin et al. 1999) and our own analyses indicate high among individual polymorphism in the macromolecular composition of $R$. arvalis jelly overall (Shu et al. 2016) as 
404 well as in glycans. Given the complexity of O-linked glycosylation it is not surprising that

405 multiple glycosylation genes are highly expressed in the $R$. arvalis oviduct - and the genetic

406 basis of jelly coat mediated adaptive maternal effects could be complex.

407 In general, the genes representing likely candidate genes for egg jelly coat formation did show a 408 different expression pattern compared to the global profile (Fig. 7). For instance, Mucin-5AC 409 and Mucin-5B (i.e. the major components of jelly core proteins), were relatively highly 410 expressed in the $[\mathrm{T}]$ individuals. However, expression of the putative jelly coat genes was very 411 diverse across the six individuals in our data set (Fig. 7). More detailed analyses on coding 412 versus regulatory variation underlying this heterogeneity as well as SNP genotyping of allelic 413 variation across the acidification gradient are important future avenues. However, it is important 414 to note that the current data only provide the first step. Future study should test to what extent 415 variation is due to coding and/or transcriptional differences in the maternally influenced jelly 416 coat (which, in turn, affects embryonic survival).

417 The potential complexity of the jelly phenotype and its function is also highlighted in the high 418 degree of variation in expression of the putative jelly coat genes across different individuals in 419 our study (Fig. 7). Given the many important roles that the egg jelly coats play in sperm-egg interactions, pathogen defense, and responses to various environmental stressors (reviewed in

421 (Menkhorst \& Selwood 2008; Shu et al. 2015b)), this complexity is not surprising. Follow up work establishing the links between the genotype (jelly coat coding genes and variation in the expression) - phenotype (jelly coat glycome) - fitness (embryonic acid tolerance) map needed to confirm the role of the candidate genes is ongoing in our lab.

Conclusions

426 In conclusion, we identified several mucin and O-linked glycosylation genes that are highly expressed in the oviduct of $R$. arvalis - and show high heterogeneity in expression. Given the role of $R$. arvalis in a broad range of evolutionary ecological questions, we believe this transcriptomic dataset together with the predicted SSR and SNP markers (Supporting information) will benefit future studies of molecular ecology and evolution in natural populations. We further hope that our oviduct transcriptomes lay the ground for future studies on the molecular evolution of jelly coat genes, thereby contributing to the emerging field of glycobiology in evolutionary ecology (Shu et al. 2015b; Springer \& Gagneux 2016), as well as 
434

435

436

437

438

439

440

441

442

443

444

445

446

447

448

449

450

451

452

453

454

455

456

457

458

459

460

461

462

463

464

465

466

467

468

469

470

471

472

studies on how these genes contribute to responses to natural selection at early life stages and adaptive divergence of local populations in particular. In particular, we hope that the genes identified here will aid in disentangling the genetic architecture of egg coat evolution and adaptive maternal effects.

\section{Acknowledgements}

We thank Anssi Laurila for generous access to research facilities and Beatrice Lindgren for invaluable help in the field and laboratory. We thank particularly Ellen Menkhorst, Daniel Jeffries, Alice Dennis, Tyler Larsen, and an anonymous reviewer for valuable comments on earlier drafts of this manuscript as well as the Genetic Diversity Center (GDC) of ETH-Zurich for advice on genetic analyses.

\section{References}

Bernardo J. 1996. The particular maternal effect of propagule size, especially egg size: Patterns, models, quality of evidence and interpretations. American Zoologist 36:216-236.

Birol I, Behsaz B, Hammond SA, Kucuk E, Veldhoen N, and Helbing CC. 2015. De novo Transcriptome Assemblies of Rana (Lithobates) catesbeiana and Xenopus laevis Tadpole Livers for Comparative Genomics without Reference Genomes. Plos One 10. ARTN e0130720 10.1371/journal.pone.0130720

Brelsford A, Lavanchy G, Sermier R, Rausch A, and Perrin N. 2017. Identifying homomorphic sex chromosomes from wild-caught adults with limited genomic resources. Molecular Ecology Resources 17:752-759. 10.1111/1755-0998.12624

Calboli FCF, Fisher MC, Garner TWJ, and Jehle R. 2011. The need for jumpstarting amphibian genome projects. Trends in Ecology \& Evolution 26:378-379. 10.1016/j.tree.2011.04.006

Claw KG, and Swanson WJ. 2012. Evolution of the Egg: New Findings and Challenges. In: Chakravarti A, and Green E, eds. Annual Review of Genomics and Human Genetics, Vol 13. Palo Alto: Annual Reviews, 109-125.

Coppin A, Maes E, Flahaut C, Coddeville B, and Strecker G. 1999. Acquisition of speciesspecific O-linked carbohydrate chains from oviducal mucins in Rana arvalis - A case study. European Journal of Biochemistry 266:370-382.

Delplace F, Maes E, Lemoine J, and Strecker G. 2002. Species specificity of O-linked carbohydrate chains of the oviducal mucins in amphibians: structural analysis of neutral oligosaccharide alditols released by reductive beta-elimination from the egg-jelly coats of Rana clamitans. Biochemical Journal 363:457-471.

Egea-Serrano A, Hangartner S, Laurila A, and Rasanen K. 2014. Multifarious selection through environmental change: acidity and predator-mediated adaptive divergence in the moor frog (Rana arvalis). Proceedings of the Royal Society B-Biological Sciences 281. Unsp 20133266 Doi 10.1098/Rspb.2013.3266

Elewa A, Wang H, Talavera-Lopez C, Joven A, Brito G, Kumar A, Hameed LS, PenradMobayed M, Yao ZY, Zamani N, Abbas Y, Abdullayev I, Sandberg R, Grabherr M, Andersson B, and Simon A. 2017. Reading and editing the Pleurodeles waltl genome 
reveals novel features of tetrapod regeneration. Nature Communications 8. Artn 2286 10.1038/S41467-017-01964-9

Gomez-Mestre I, Touchon JC, and Warkentin KM. 2006. Amphibian embryo and parental defenses and a larval predator reduce egg mortality from water mold. Ecology 87:25702581. Doi 10.1890/0012-9658(2006)87[2570:Aeapda]2.0.Co;2

Gotz S, Garcia-Gomez JM, Terol J, Williams TD, Nagaraj SH, Nueda MJ, Robles M, Talon M, Dopazo J, and Conesa A. 2008. High-throughput functional annotation and data mining with the Blast2GO suite. Nucleic Acids Research 36:3420-3435. 10.1093/nar/gkn176

Grabherr MG, Haas BJ, Yassour M, Levin JZ, Thompson DA, Amit I, Adiconis X, Fan L, Raychowdhury R, Zeng QD, Chen ZH, Mauceli E, Hacohen N, Gnirke A, Rhind N, di Palma F, Birren BW, Nusbaum C, Lindblad-Toh K, Friedman N, and Regev A. 2011. Full-length transcriptome assembly from RNA-Seq data without a reference genome. Nature Biotechnology 29:644-U130. 10.1038/nbt.1883

Guerardel Y, Kol O, Maes E, Lefebvre T, Boilly B, Davril M, and Strecker G. 2000. O-glycan variability of egg-jelly mucins from Xenopus laevis: characterization of four phenotypes that differ by the terminal glycosylation of their mucins. Biochemical Journal 352:449463.

Hammond SA, Warren RL, Vandervalk BP, Kucuk E, Khan H, Gibb EA, Pandoh P, Kirk H, Zhao YJ, Jones M, Mungall AJ, Coope R, Pleasance S, Moore RA, Holt RA, Round JM, Ohora S, Walle BV, Veldhoen N, Helbing CC, and Birol I. 2017. The North American bullfrog draft genome provides insight into hormonal regulation of long noncoding RNA. Nature Communications 8. Artn 1433 10.1038/S41467-017-01316-7

Hangartner S, Laurila A, and Rasanen K. 2011. Adaptive divergence of the moor frog (Rana arvalis) along an acidification gradient. Bmc Evolutionary Biology 11. 366 10.1186/14712148-11-366

Hangartner S, Laurila A, and Rasanen K. 2012. The quantitative genetic basis of adaptive divergence in the moor frog (Rana arvalis) and its implications for gene flow. Journal of Evolutionary Biology 25:1587-1599. 10.1111/j.1420-9101.2012.02546.x

Hedrick JL. 2008. Anuran and pig egg zona pellucida glycoproteins in fertilization and early development. International Journal of Developmental Biology 52:683-701. DOI 10.1387/ijdb.082580jh

Hedrick JL, and Nishihara T. 1991. Structure and Function of the Extracellular-Matrix of Anuran Eggs. Journal of Electron Microscopy Technique 17:319-335.

Helbing CC. 2012. The metamorphosis of amphibian toxicogenomics. Front Genet 3:37. 10.3389/fgene.2012.00037

Hellsten U, Harland RM, Gilchrist MJ, Hendrix D, Jurka J, Kapitonov V, Ovcharenko I, Putnam NH, Shu SQ, Taher L, Blitz IL, Blumberg B, Dichmann DS, Dubchak I, Amaya E, Detter JC, Fletcher R, Gerhard DS, Goodstein D, Graves T, Grigoriev IV, Grimwood J, Kawashima T, Lindquist E, Lucas SM, Mead PE, Mitros T, Ogino H, Ohta Y, Poliakov AV, Pollet N, Robert J, Salamov A, Sater AK, Schmutz J, Terry A, Vize PD, Warren WC, Wells D, Wills A, Wilson RK, Zimmerman LB, Zorn AM, Grainger R, Grammer T, Khokha MK, Richardson PM, and Rokhsar DS. 2010. The Genome of the Western Clawed Frog Xenopus tropicalis. Science 328:633-636. 10.1126/science.1183670

Hof C, Araujo MB, Jetz W, and Rahbek C. 2011. Additive threats from pathogens, climate and land-use change for global amphibian diversity. Nature 480:516-519. 10.1038 /nature 10650 
519 Houle D, Govindaraju DR, and Omholt S. 2010. Phenomics: the next challenge. Nature Reviews $520 \quad$ Genetics 11:855-866. 10.1038/nrg2897

521

522

523

Iseli C, Jongeneel CV, and Bucher P. 1999. ESTScan: a program for detecting, evaluating, and reconstructing potential coding regions in EST sequences. Proc Int Conf Intell Syst Mol Biol:138-148.

Kanehisa M, Araki M, Goto S, Hattori M, Hirakawa M, Itoh M, Katayama T, Kawashima S, Okuda S, Tokimatsu T, and Yamanishi Y. 2008. KEGG for linking genomes to life and the environment. Nucleic Acids Research 36:480-484. 10.1093/nar/gkm882

Lang TG, Klasson S, Larsson E, Johansson MEV, Hansson GC, and Samuelsson T. 2016. Searching the Evolutionary Origin of Epithelial Mucus Protein Components-Mucins and FCGBP. Molecular Biology and Evolution 33:1921-1936. 10.1093/molbev/msw066

Li RQ, Li YR, Kristiansen K, and Wang J. 2008. SOAP: short oligonucleotide alignment program. Bioinformatics 24:713-714. 10.1093/bioinformatics/btn025

Lopez-Maestre H, Brinza L, Marchet C, Kielbassa J, Bastien S, Boutigny M, Monnin D, El Filali A, Carareto CM, Vieira C, Picard F, Kremer N, Vavre F, Sagot MF, and Lacroix V. 2016. SNP calling from RNA-seq data without a reference genome: identification, quantification, differential analysis and impact on the protein sequence. Nucleic Acids Research 44:e148. 10.1093/nar/gkw655

Menkhorst E, and Selwood L. 2008. Vertebrate Extracellular Preovulatory and Postovulatory Egg Coats. Biology of Reproduction 79:790-797. 10.1095/biolreprod.108.068551

Mitchell-Olds T, Willis JH, and Goldstein DB. 2007. Which evolutionary processes influence natural genetic variation for phenotypic traits? Nature Reviews Genetics 8:845-856. Doi 10.1038/Nrg2207

Morin PA, Luikart G, Wayne RK, and Grp SW. 2004. SNPs in ecology, evolution and conservation. Trends in Ecology \& Evolution 19:208-216. 10.1016/j.tree.2004.01.009

Mortazavi A, Williams BA, McCue K, Schaeffer L, and Wold B. 2008. Mapping and quantifying mammalian transcriptomes by RNA-Seq. Nat Methods 5:621-628. 10.1038/nmeth.1226

Mousseau TA, and Fox CW. 1998. The adaptive significance of maternal effects. Trends in Ecology \& Evolution 13:403-407.

Nadeau NJ, and Jiggins CD. 2010. A golden age for evolutionary genetics? Genomic studies of adaptation in natural populations. Trends in Genetics 26:484-492. DOI 10.1016/j.tig.2010.08.004

Nowoshilow S, Schloissnig S, Fei JF, Dahl A, Pang AWC, Pippel M, Winkler S, Hastie AR, Young G, Roscito JG, Falcon F, Knapp D, Powell S, Cruz A, Cao H, Habermann B, Hiller M, Tanaka EM, and Myers EW. 2018. The axolotl genome and the evolution of key tissue formation regulators. Nature 554:50-55. 10.1038/nature25458

Palumbi SR. 2009. Speciation and the evolution of gamete recognition genes: pattern and process. Heredity 102:66-76. Doi 10.1038/Hdy.2008.104

Papantonis A, Swevers L, and Iatrou K. 2015. Chorion Genes: A Landscape of Their Evolution, Structure, and Regulation. Annual Review of Entomology 60:177-194. 10.1146/annurevento-010814-020810

Persson M, Räsänen K, Laurila A, and Merilä J. 2007. Maternally determined adaptation to acidity in Rana arvalis: Are laboratory and field estimates of embryonic stress tolerance congruent? Canadian Journal of Zoology-Revue Canadienne De Zoologie 85:832-838. Doi 10.1139/Z07-064 
564

565

566

567

568

569

570

571

572

573

574

575

576

577

578

579

580

581

582

583

584

585

586

587

588

589

590

591

592

593

594

595

596

597

598

599

600

601

602

603

604

605

606

607

608

Price SJ, Garner TWJ, Balloux F, Ruis C, Paszkiewicz KH, Moore K, and Griffiths AGF. 2015. A de novo Assembly of the Common Frog (Rana temporaria) Transcriptome and Comparison of Transcription Following Exposure to Ranavirus and Batrachochytrium dendrobatidis. Plos One 10. ARTN e0130500 10.1371/journal.pone.0130500

Qiao L, Yang WZ, Fu JZ, and Song ZB. 2013. Transcriptome Profile of the Green Odorous Frog (Odorrana margaretae). Plos One 8. ARTN e75211 10.1371/journal.pone.0075211

Räsänen K, and Kruuk LEB. 2007. Maternal effects and evolution at ecological time-scales. Functional Ecology 21:408-421. DOI 10.1111/j.1365-2435.2007.01246.x

Räsänen K, Laurila A, and Merilä J. 2003a. Geographic variation in acid stress tolerance of the moor frog, Rana arvalis. I. Local adaptation. Evolution 57:352-362.

Räsänen K, Laurila A, and Merilä J. 2003b. Geographic variation in acid stress tolerance of the moor frog, Rana arvalis. II. Adaptive maternal effects. Evolution 57:363-371.

Richter-Boix A, Quintela M, Segelbacher G, and Laurila A. 2011. Genetic analysis of differentiation among breeding ponds reveals a candidate gene for local adaptation in Rana arvalis. Molecular Ecology 20:1582-1600. 10.1111/j.1365-294X.2011.05025.x

Robertson LS, and Cornman RS. 2014. Transcriptome resources for the frogs Lithobates clamitans and Pseudacris regilla, emphasizing antimicrobial peptides and conserved loci for phylogenetics. Molecular Ecology Resources 14:178-183. 10.1111/1755-0998.12164

Santos JC, Tarvin RD, O'Connell LA, Blackburn DC, and Coloma LA. 2018. Diversity within diversity: Parasite species richness in poison frogs assessed by transcriptomics. Molecular Phylogenetics and Evolution 125:40-50. https://doi.org/10.1016/j.ympev.2018.03.015

Schroeder A, Mueller O, Stocker S, Salowsky R, Leiber M, Gassmann M, Lightfoot S, Menzel W, Granzow M, and Ragg T. 2006. The RIN: an RNA integrity number for assigning integrity values to RNA measurements. Bmc Molecular Biology 7. Artn 3 10.1186/14712199-7-3

Schunter C, Garza JC, Macpherson E, and Pascual M. 2014. SNP development from RNA-seq data in a nonmodel fish: how many individuals are needed for accurate allele frequency prediction? Molecular Ecology Resources 14:157-165. Doi 10.1111/1755-0998.12155

Sears BF, Schlunk AD, and Rohr JR. 2012. Do Parasitic Trematode Cercariae Demonstrate a Preference for Susceptible Host Species? Plos One 7. ARTN e51012 10.1371/journal.pone.0051012

Shu L, Laurila A, and Rasanen K. 2015a. Acid stress mediated adaptive divergence in ion channel function during embryogenesis in Rana arvalis. Scientific Reports 5:14201. $10.1038 /$ srep 14201

Shu L, Laurila A, Suter MJF, and Räsänen K. 2016. Molecular phenotyping of maternally mediated parallel adaptive divergence within Rana arvalis and Rana temporaria. Molecular Ecology 25:4564-4579. 10.1111/mec.13786

Shu L, Suter M, and Rasanen K. 2015b. Evolution of egg coats: linking molecular biology and ecology. Molecular Ecology 24:4052-4073. 10.1111/mec.13283

Shu L, Suter MF, Laurila A, and Räsänen K. 2015c. Mechanistic basis of adaptive maternal effects: egg jelly water balance mediates embryonic adaptation to acidity in Rana arvalis. Oecologia 179:617-628. 10.1007/s00442-015-3332-4

Springer SA, and Gagneux P. 2016. Glycomics: revealing the dynamic ecology and evolution of sugar molecules. J Proteomics 135:90-100. 10.1016/j.jprot.2015.11.022 
609

610

611

612

613

614

615

616

617

618

619

620

621

622

623

624

625

626

627

628

629

630

631

632

633

634

635

636

637

638

639

640

641

642

643

644

645

646

647

Strecker G, Coppin A, Florea D, Maes E, and Cogalniceanu D. 2003. Comparative study of carbohydrate chains released from the oviducal mucins of the two very closely related amphibian species Bombina bombina and Bombina variegata. Biochimie 85:53-64. Doi 10.1016/S0300-9084(03)00021-X

Stuart SN, Chanson JS, Cox NA, Young BE, Rodrigues ASL, Fischman DL, and Waller RW. 2004. Status and trends of amphibian declines and extinctions worldwide. Science 306:1783-1786. 10.1126/science.1103538

Sun YB, Xiong ZJ, Xiang XY, Liu SP, Zhou WW, Tu XL, Zhong L, Wang L, Wu DD, Zhang BL, Zhu CL, Yang MM, Chen HM, Li F, Zhou L, Feng SH, Huang C, Zhang GJ, Irwin D, Hillis DM, Murphy RW, Yang HM, Che J, Wang J, and Zhang YP. 2015. Wholegenome sequence of the Tibetan frog Nanorana parkeri and the comparative evolution of tetrapod genomes. Proceedings of the National Academy of Sciences of the United States of America 112:1257-1262. 10.1073/pnas.1501764112

Tarazona S, Garcia-Alcalde F, Dopazo J, Ferrer A, and Conesa A. 2011. Differential expression in RNA-seq: A matter of depth. Genome Research 21:2213-2223. 10.1101/gr.124321.111

Todd EV, Black MA, and Gemmell NJ. 2016. The power and promise of RNA-seq in ecology and evolution. Molecular Ecology 25:1224-1241. 10.1111/mec.13526

Tong ZB, Gold L, Pfeifer KE, Dorward H, Lee E, Bondy CA, Dean J, and Nelson LM. 2000. Mater, a maternal effect gene required for early embryonic development in mice. Nature Genetics 26:267-268.

Van Buskirk J, and Arioli M. 2005. Habitat specialization and adaptive phenotypic divergence of anuran populations. Journal of Evolutionary Biology 18:596-608. 10.1111/j.14209101.2004.00869.x

Wang Z, Gerstein M, and Snyder M. 2009. RNA-Seq: a revolutionary tool for transcriptomics. Nature Reviews Genetics 10:57-63. Doi 10.1038/Nrg2484

Wolf JB, Brodie ED, Cheverud JM, Moore AJ, and Wade MJ. 1998. Evolutionary consequences of indirect genetic effects. Trends in Ecology \& Evolution 13:64-69. Doi 10.1016/S01695347(97)01233-0

Wong JL, and Wessel GM. 2006. Defending the zygote: Search for the ancestral animal block to polyspermy. Current Topics in Developmental Biology 72:1-151. Doi 10.1016/S00702153(05)72001-9

Wu XM, Viveiros MM, Eppig JJ, Bai YC, Fitzpatrick SL, and Matzuk MM. 2003. Zygote arrest 1 (Zar1) is a novel maternal-effect gene critical for the oocyte-to-embryo transition. Nature Genetics 33:187-191. 10.1038/ng1079

Zhang M, Li YT, Yao BJ, Sun MY, Wang ZW, and Zhao Y. 2013. Transcriptome Sequencing and de novo Analysis for Oviductus Ranae of Rana chensinensis Using Illumina RNASeq Technology. Journal of Genetics and Genomics 40:137-140. 10.1016/j.jgg.2013.01.004 


\section{Figure 1}

The length distribution of the unigenes identified based on seven $R$. arvalis oviduct transcriptomes

The $\mathrm{X}$-axis shows the length distribution (nt) of sequenced unigenes and $\mathrm{Y}$ axis indicates number of unigenes for a given length

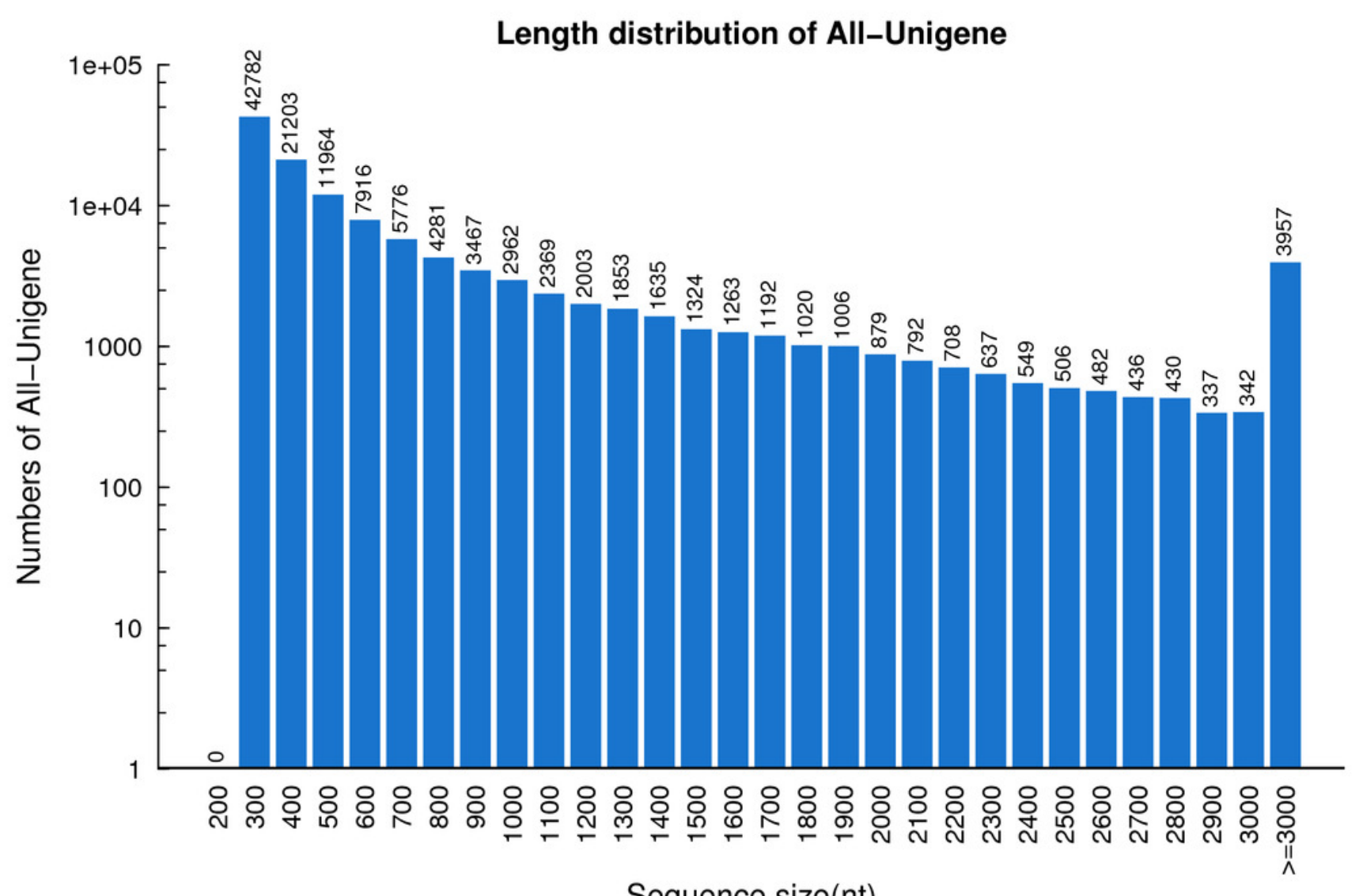

Sequence size(nt) 
Figure 2

Annotation of $R$. arvalis unigenes against the $\mathrm{Nr}$ database.

(A) E-value distribution of the top BLAST hits for each unique sequence; (B) Similarity

distribution of the top BLAST hits for each unique sequence; (C) Species distribution of the top BLAST hits for all homologous sequences. 
A. E-value Distribution

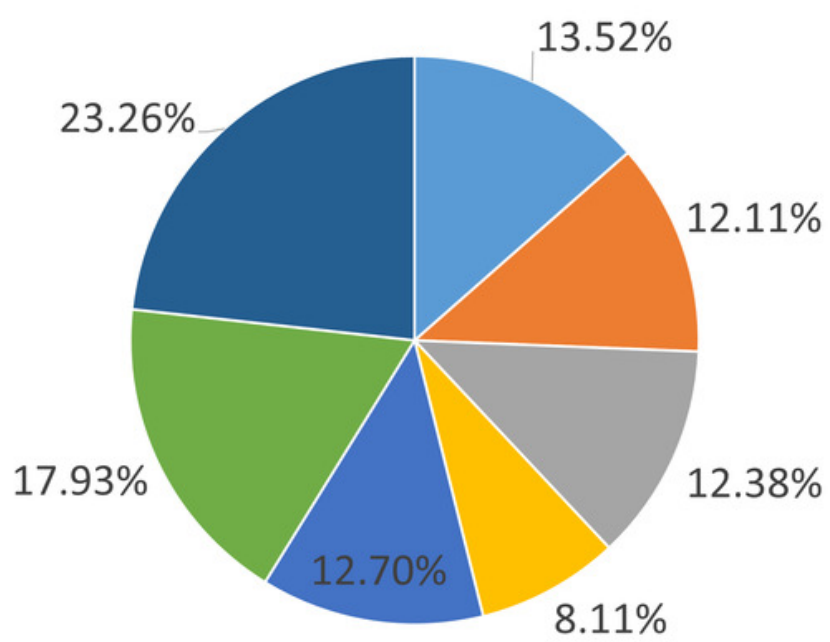

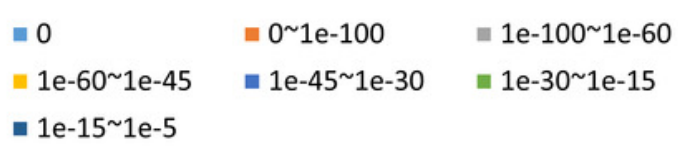

B. Similarity Distribution

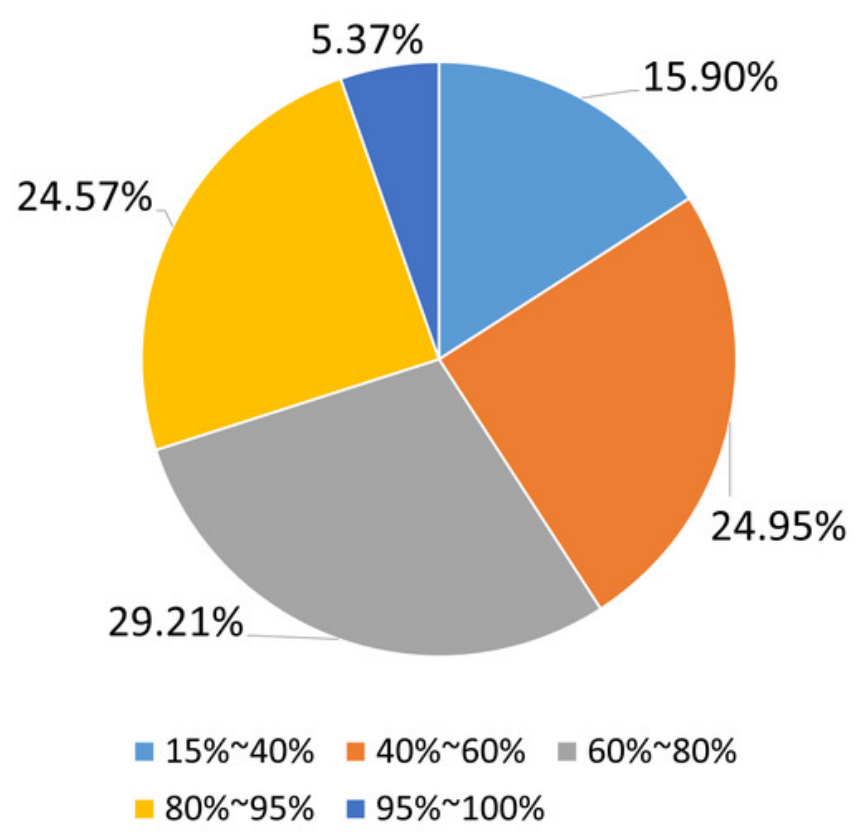

\section{Species Distribution}

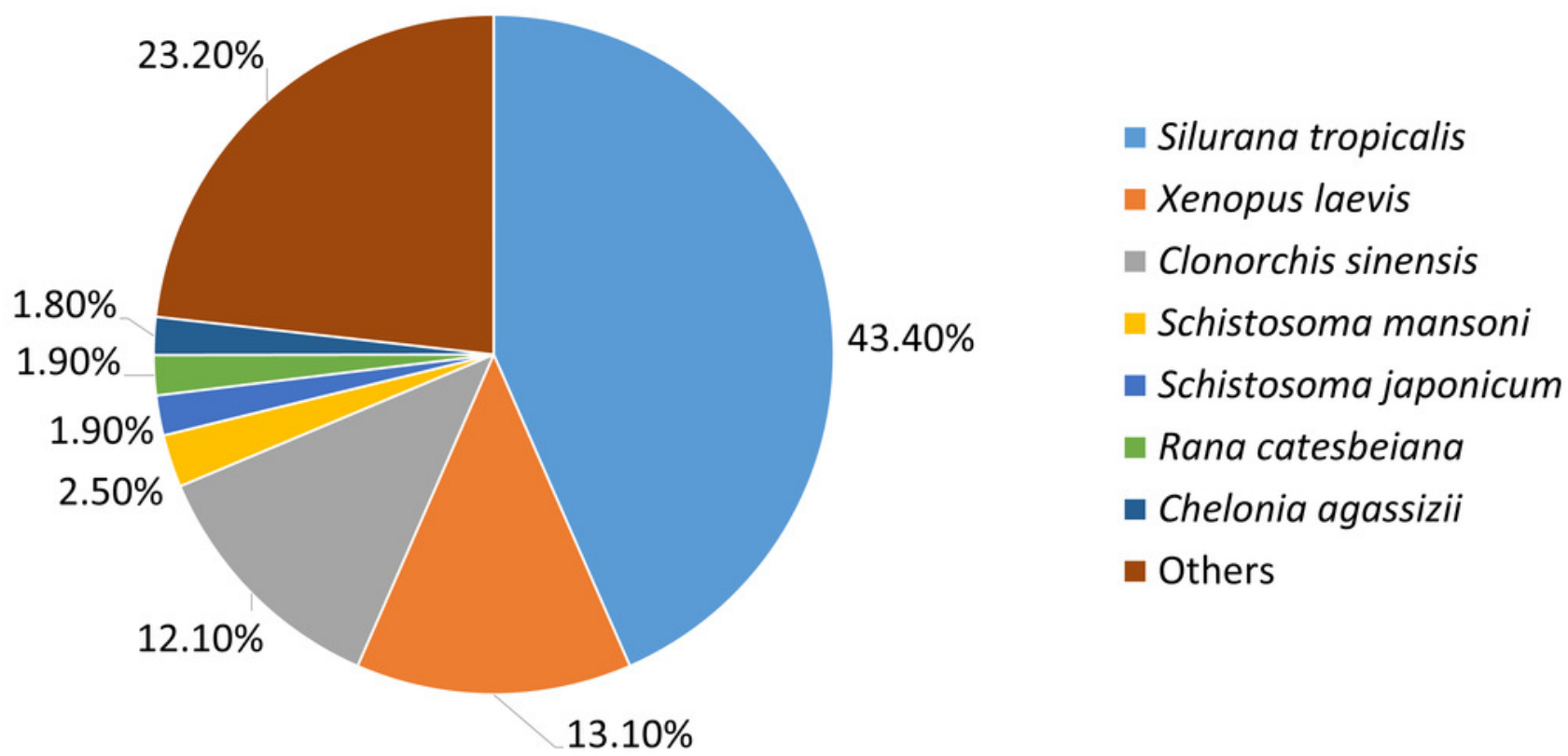


Figure 3

COG functional classification of $R$. arvalis unigenes .

The $\mathrm{X}$-axis shows the different functional classes, and $\mathrm{Y}$-axis the number of genes annotated into a given class. Most genes are in the classes of "General function", followed by "Translation, ribosomal structure and biogenesis", "Transcription" and "Replication, recombination, repair".

\section{COG Function Classification of All-Unigene.fa Sequence}

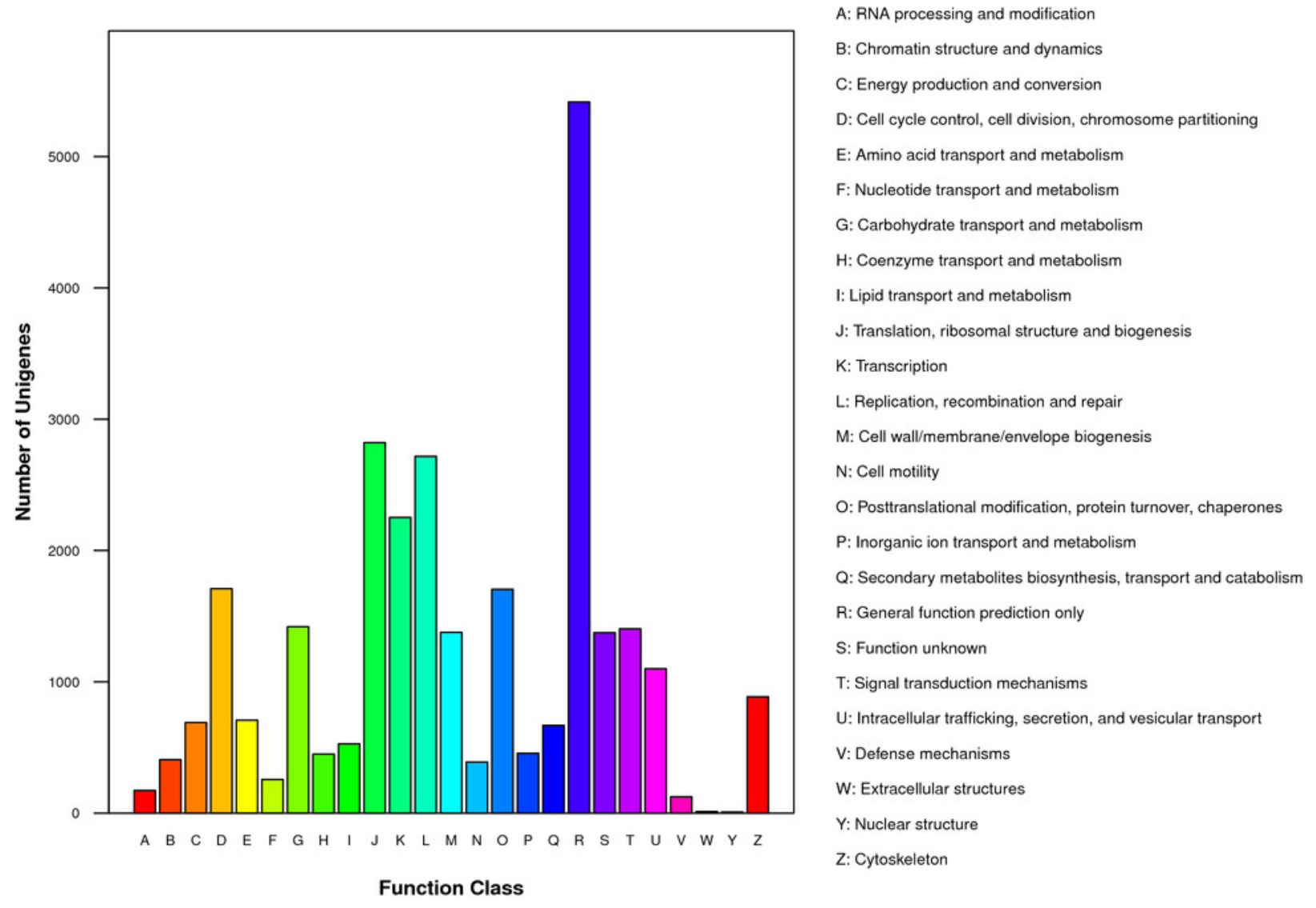




\section{Figure 4}

Number of unigenes annotated based on different public databases (see methods for details on databases).

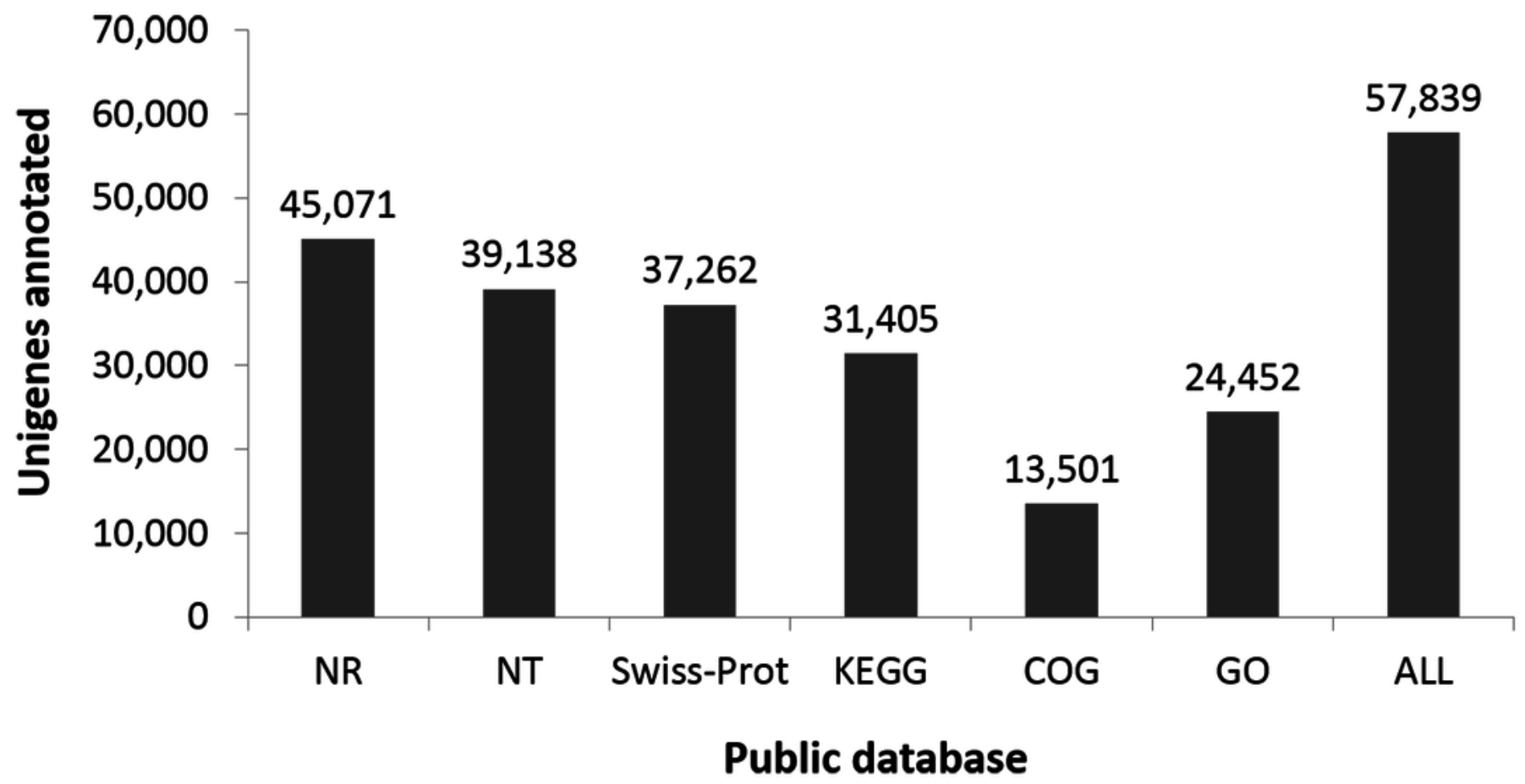


Figure $\mathbf{5}$ (on next page)

GO categories of unigenes identified from the transcriptome of seven $R$. arvalis oviduct samples.

The unigenes were annotated in three categories as represented on the X-axis: biological processes (23), cellular components (18) and molecular functions (19). The X-axis indicates the $\mathrm{GO}$ term, while the $\mathrm{Y}$-axis (log scale) indicates the number and percentage of unigenes for each GO term. 


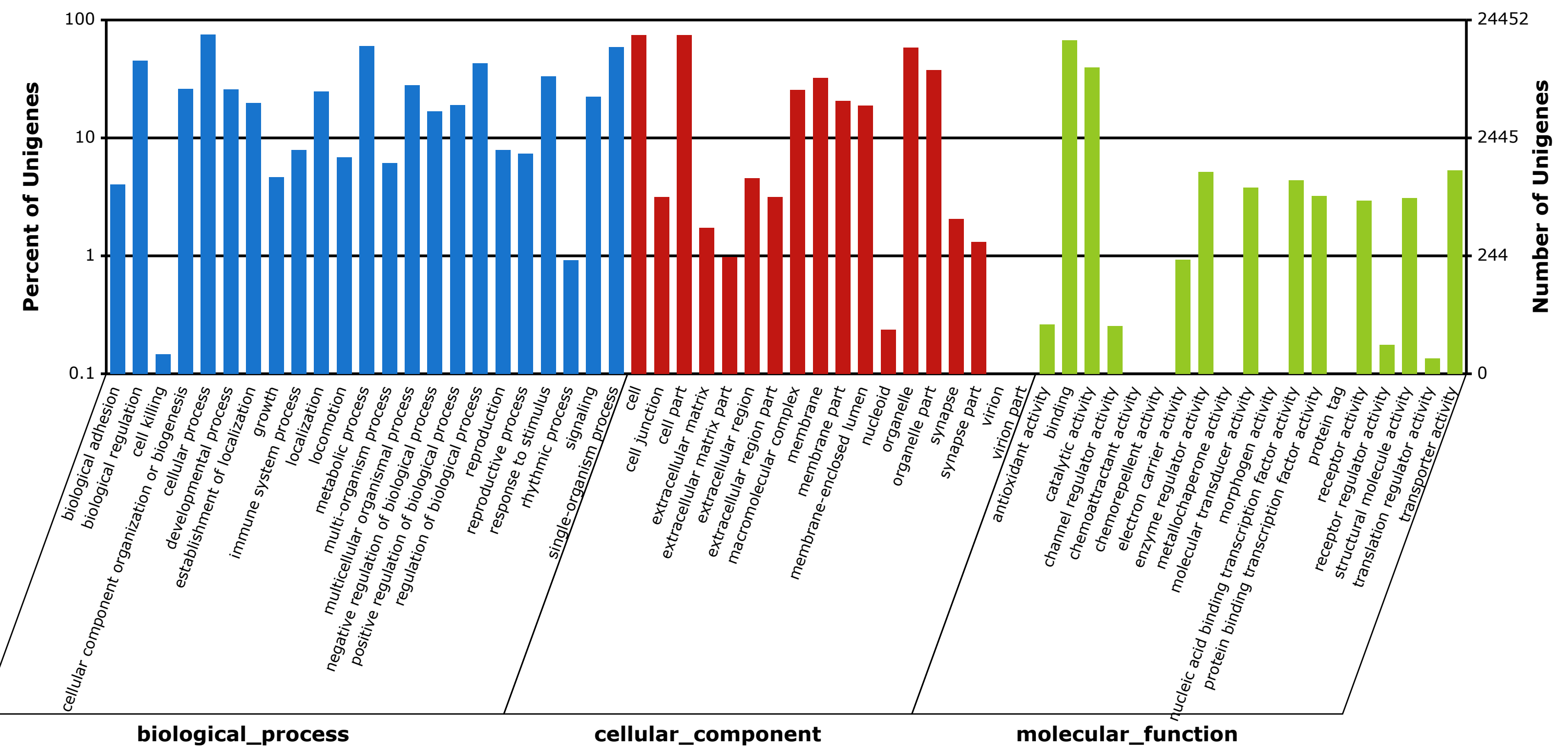




\section{Figure 6}

The biosynthesis pathway (KEGG) of the Mucin type O-glycans.

Red squares indicate the genes expressed in the oviduct of $R$. arvalis. Abbreviation and full names of genes: GALNT, Polypeptide N-acetylgalactosaminyltransferase; SIAT4, sialyltransferase 4A; SIAT7A, sialyltransferase 7A; C1GALT1, glycoprotein-Nacetylgalactosamine 3-beta-galactosyltransferase; GCNT1, beta-1,3-galactosyl-0-glycosylglycoprotein beta-1,6-N-acetylglucosaminyltransferase; B3GNT6, acetylgalactosaminyl-Oglycosyl-glycoprotein beta-1,3-N-acetylglucosaminyltransferase; GCNT3, Nacetylglucosaminyltransferase 3, mucin type; B4GALT5, beta-1,4-galactosyltransferase 5 . 


\section{MUCIN TYPE O-GLYCAN BIOSYNTHESIS}

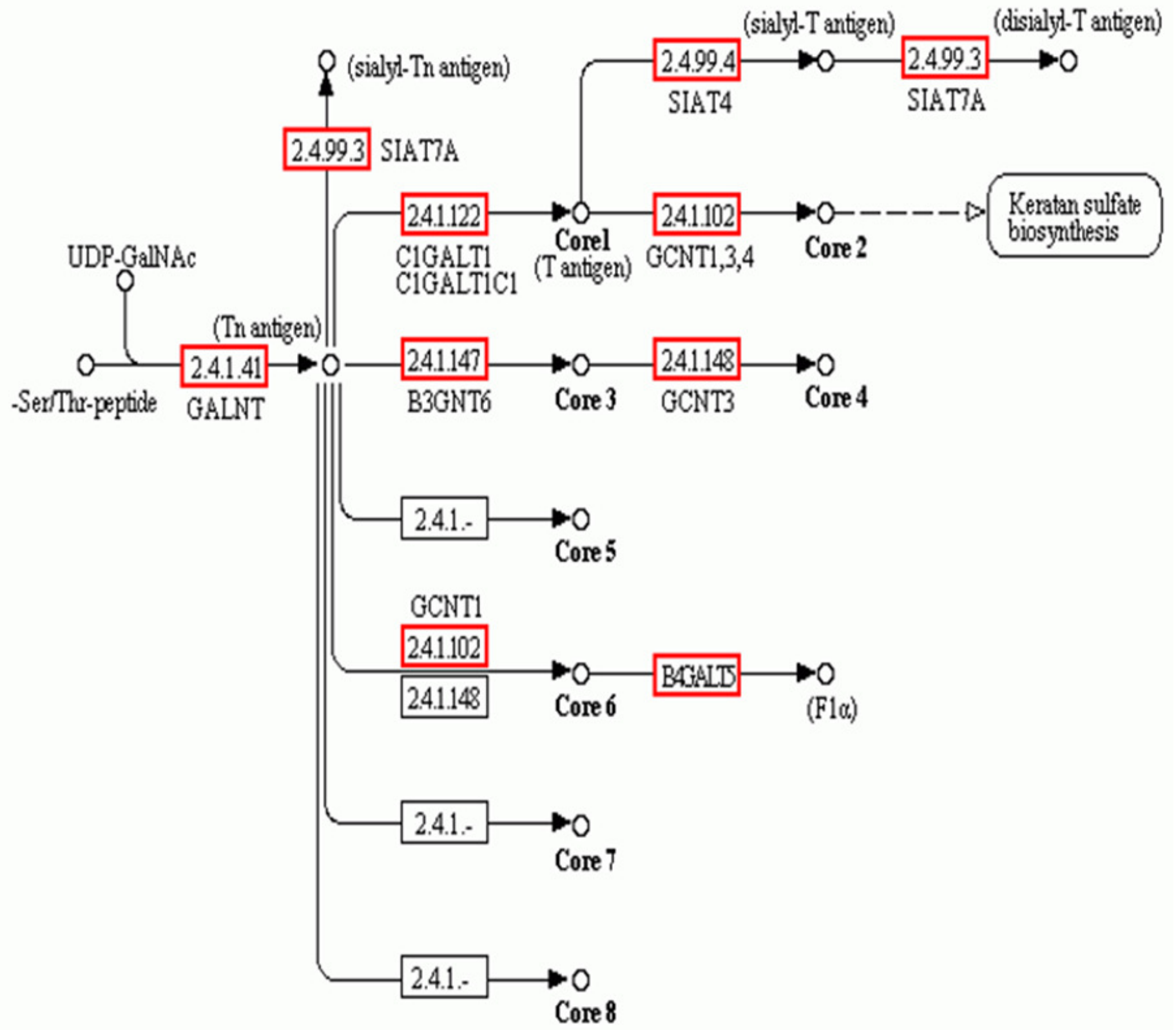




\section{Figure 7 (on next page)}

Heat map of gene expression in oviducts of six $R$. arvalis females.

The genes presented are selected from those that coding for core proteins (in grey) and protein glycosylation (in black). The colors represent high (red), low (green) or average (black) gene expression based on Z-score normalized FPKM values for each gene. The individual female's identity from the three study populations (T, $S$ and $B$ ) is indicated below. Within each population, the number indicates the individual female, whereby the females with the most sensitive embryos is indicated by 1 and female with the most acid tolerant embryos is indicated by 2 (acid tolerance was estimated in Shu et al. 2015b). B3 female was left out from this analysis because it had not fully ovulated at the time of sampling and hence was not directly comparable in gene expression patterns. 


\section{Table $\mathbf{1}$ (on next page)}

Results of RNA sequencing of six $R$. arvalis oviducts.

Total reads and total nucleotides are given after adaptor trimming and quality filtering. Q20 percentage is the proportion of nucleotides with a quality value larger than 20; GC percentage is the proportion of guanidine and cytosine nucleotides among total nucleotides. The sample ID indicates the six different females, originating from three populations $(S=$ neutral origin, $\mathrm{T}=$ acid origin and $\mathrm{B}=$ intermediate $\mathrm{pH}$ origin). The individuals were chosen so as to maximize variation in embryonic acid tolerance (which in turn is largely determined by the molecular composition of the egg jelly coats). In each population, individual 1 (italics) represents a female whose offspring was most acid sensitive in the embryonic stage, while individual 2 represents the most acid tolerant offspring (based on screening of embryonic acid tolerance in a laboratory experiment, Shu et al. 2016). 


\begin{tabular}{cccccc}
\hline Sample & Total Raw & Total Clean & Total Clean & Q20 & GC \\
ID & Reads & Reads & Nucleotides & percentage & percentage \\
\hline$S 1$ & $99,177,178$ & $86,475,930$ & $7,782,833,700$ & $98.09 \%$ & $44.68 \%$ \\
S2 & $99,884,602$ & $87,485,924$ & $7,873,733,160$ & $98.04 \%$ & $45.11 \%$ \\
B1 & $92,353,906$ & $81,166,804$ & $7,305,012,360$ & $98.07 \%$ & $44.92 \%$ \\
B2 & $96,108,078$ & $85,373,136$ & $7,683,582,240$ & $98.05 \%$ & $44.83 \%$ \\
$T 1$ & $95,886,666$ & $84,428,864$ & $7,598,597,760$ & $98.10 \%$ & $44.74 \%$ \\
T2 & $108,026,198$ & $84,548,126$ & $7,609,331,340$ & $98.27 \%$ & $45.68 \%$ \\
\hline
\end{tabular}

1 


\section{Table 2 (on next page)}

Contigs and unigenes in the transcriptome assembly of six $R$. arvalis oviducts.

The sample ID indicates the six different females, originating from three populations $(\mathrm{S}=$ neutral origin, $\mathrm{T}=$ acid origin and $\mathrm{B}=$ intermediate $\mathrm{pH}$ origin). $\mathrm{N} 50$ is the shortest sequence length at $50 \%$ of the transcriptome. Total Consensus Sequences represents the all assembled unigenes. Distinct Clusters represents the cluster unigenes. The same cluster contains some high similar (more than 70\%) unigenes, and these unigenes may come from same gene or homologous gene. Distinct Singletons represents this unigene come from a single gene. 
Table 2. Contigs and unigenes in the transcriptome assembly of seven $\boldsymbol{R}$. arvalis oviducts. The sample ID indicates the seven different females, originating from three populations $(\mathrm{S}=$ neutral origin, $\mathrm{T}=$ acid origin and $\mathrm{B}=$ intermediate $\mathrm{pH}$ origin). The $\mathrm{B} 3$ individual (in grey) had not yet fully ovulated at the time of sampling (see material and methods section for further details). N50 is the shortest sequence length at $50 \%$ of the transcriptome. Total Consensus Sequences represents the all assembled unigenes. Distinct Clusters represents the cluster unigenes. The same cluster contains some high similar (more than 70\%) unigenes, and these unigenes may come from same gene or homologous gene. Distinct Singletons represents this unigene come from a single gene.

\begin{tabular}{|c|c|c|c|c|c|c|c|c|}
\hline & $\begin{array}{c}\text { Sample } \\
\text { ID }\end{array}$ & $\begin{array}{c}\text { Total } \\
\text { Number }\end{array}$ & $\begin{array}{c}\text { Total Length } \\
\text { (nt) }\end{array}$ & $\begin{array}{c}\text { Mean } \\
\text { Length (nt) }\end{array}$ & N50 & $\begin{array}{c}\text { Total Consensus } \\
\text { Sequences }\end{array}$ & $\begin{array}{l}\text { Distinct } \\
\text { Clusters }\end{array}$ & $\begin{array}{c}\text { Distinct } \\
\text { Singletons }\end{array}$ \\
\hline \multirow[t]{6}{*}{ Contig } & $\overline{S 1}$ & 194,272 & $53,890,758$ & 277 & 362 & - & - & - \\
\hline & $\mathrm{S} 2$ & 217,356 & $59,657,739$ & 274 & 366 & - & - & - \\
\hline & $B 1$ & 174,223 & $49,240,955$ & 283 & 392 & - & - & - \\
\hline & B2 & 183,977 & $51,106,261$ & 278 & 381 & - & - & - \\
\hline & $T 1$ & 160,756 & $43,939,551$ & 273 & 342 & - & - & - \\
\hline & $\mathrm{T} 2$ & 153,751 & $46,501,333$ & 302 & 436 & - & - & - \\
\hline \multirow[t]{7}{*}{ Unigene } & $S 1$ & 104,705 & $50,126,396$ & 479 & 693 & 104,705 & 15,515 & 89,190 \\
\hline & $\mathrm{S} 2$ & 112,136 & $55,372,134$ & 494 & 729 & 112,136 & 16,008 & 96,128 \\
\hline & $B 1$ & 90,424 & $46,895,863$ & 519 & 830 & 90,424 & 13,740 & 76,684 \\
\hline & B2 & 91,647 & $47,344,659$ & 517 & 787 & 91,647 & 14,419 & 77,228 \\
\hline & $T 1$ & 91,528 & $40,874,115$ & 447 & 632 & 91,528 & 11,288 & 80,240 \\
\hline & $\mathrm{T} 2$ & 87,401 & $45,945,512$ & 526 & 839 & 87,401 & 12,775 & 74,626 \\
\hline & All & 124,071 & $90,322,330$ & 728 & 1212 & 124,071 & 28,452 & 95,619 \\
\hline
\end{tabular}




\section{Table 3(on next page)}

Genes coding for core proteins as identified from the oviduct of six $R$. arvalis females. 


\begin{tabular}{|c|c|c|}
\hline Component & Gene & Function \\
\hline \multirow[t]{8}{*}{ Mucin } & Mucin-1 & ECM protein \\
\hline & Mucin-2 & ECM protein \\
\hline & Mucin-4 & ECM protein \\
\hline & Mucin-5AC & ECM protein \\
\hline & Mucin-5B & ECM protein \\
\hline & Mucin-6 & ECM protein \\
\hline & Mucin-7 & ECM protein \\
\hline & Mucin-15 & ECM protein \\
\hline \multirow[t]{13}{*}{ Collagen } & Collagen alpha-1(I) & ECM protein \\
\hline & Collagen alpha-1(III) & ECM protein \\
\hline & Collagen alpha-1(V) & ECM protein \\
\hline & Collagen alpha-1(XI) & ECM protein \\
\hline & Collagen alpha-1(XII) & ECM protein \\
\hline & Collagen alpha-1(XVIII) & ECM protein \\
\hline & Collagen alpha-1(XXVII) & ECM protein \\
\hline & Collagen alpha-2(I) chain & ECM protein \\
\hline & Collagen alpha-2(IV) & ECM protein \\
\hline & Collagen alpha-2(V) & ECM protein \\
\hline & Collagen alpha-2(VI) & ECM protein \\
\hline & Collagen alpha-5(IV) & ECM protein \\
\hline & Collagen alpha-6(IV) chain & ECM protein \\
\hline \multirow[t]{9}{*}{ Others } & Decorin & ECM protein \\
\hline & Dermatopontin & ECM protein \\
\hline & EMILIN-1 & ECM protein \\
\hline & EMILIN-2 & ECM protein \\
\hline & Fibrillin-1 & ECM protein \\
\hline & Fibrinogen-like protein 1 & ECM protein \\
\hline & Fibronectin & ECM protein \\
\hline & Fibulin & ECM protein \\
\hline & Laminin & ECM protein \\
\hline
\end{tabular}




\section{Table 4(on next page)}

Protein glycosylation genes as identified from the oviduct of $R$. arvalis females. 


\begin{tabular}{|c|c|c|}
\hline Glycan & Glycan type & Gene \\
\hline \multirow[t]{9}{*}{ Mucin type } & & beta-1,3-N-acetylglucosaminyltransferase \\
\hline & & alpha-N-acetylgalactosaminide alpha-2,6- \\
\hline & & beta-1,6-N-acetylglucosaminyltransferase \\
\hline & & beta-1,4-galactosyltransferase 5 \\
\hline & & glycoprotein-N-acetylgalactosamine 3-beta- \\
\hline & & $\mathrm{N}$-acetylglucosaminyltransferase 3 , mucin type \\
\hline & & polypeptide $\mathrm{N}$-acetylgalactosaminyltransferase \\
\hline & & sialyltransferase $4 \mathrm{~A}$ \\
\hline & & sialyltransferase 7A \\
\hline \multirow[t]{15}{*}{ Other type } & O-linked GlcNAc type & Protein O-GlcNAc transferase \\
\hline & O-linked Man type & beta-1,2-N-acetylglucosaminyltransferase \\
\hline & & beta-1,4-galactosyltransferase 1 \\
\hline & & carbohydrate 3-sulfotransferase 10 \\
\hline & & dolichyl-phosphate-mannose-protein \\
\hline & & glucuronosyltransferase \\
\hline & & sialyltransferase 6 \\
\hline & & 4-galactosyl-N-acetylglucosaminide 3-alpha-L- \\
\hline & O-linked Fuc type & beta-1,4-galactosyltransferase 1 \\
\hline & & peptide-O-fucosyltransferase \\
\hline & & sialyltransferase 6 \\
\hline & O-linked Glc type & protein glucosyltransferase \\
\hline & & UDP-xylose:glucoside alpha-1,3-xylosyltransferase \\
\hline & O-linked Gal type & collagen beta-1,O-galactosyltransferase \\
\hline & & lysyl \\
\hline \multirow[t]{5}{*}{ Heparan } & & alpha-1,4-N-acetylglucosaminyltransferase EXTL3 \\
\hline & & alpha-1,4-N-acetylglucosaminyltransferase EXTL2 \\
\hline & & glucuronyl/N-acetylglucosaminyl transferase EXT1 \\
\hline & & N-deacetylase/N-sulfotransferase (heparan \\
\hline & & Heparan sulfate glucosamine 3 -O-sulfotransferase 1 \\
\hline
\end{tabular}


Chondroitin

Keratan

Keratan chondroitin sulfate N-acetylgalactosaminyltransferase

chondroitin sulfate synthase

galactosylxylosylprotein 3-beta-galactosyltransferase

galactosylgalactosylxylosylprotein 3-beta-

protein xylosyltransferase

xylosylprotein 4-beta-galactosyltransferase

beta-1,4-galactosyltransferase 1

beta-1,4-galactosyltransferase 4

beta-1,3-N-acetylglucosaminyltransferase 7

carbohydrate 6-sulfotransferase 2

$\mathrm{N}$-acetyllactosaminide beta-1,3-N-

sialyltransferase $4 \mathrm{~A}$ 